\title{
Ever-Increasing Insulin-Requiring Patients Globally
}

\author{
Satish K. Garg, MD, ${ }^{1,2}$ Amanda H. Rewers, MD, and Halis Kaan Akturk, MD ${ }^{1,2}$
}

Keywords: Type 1 diabetes, Type 2 diabetes, Insulin analogues, Global economic burden, Severe hypoglycemia, Diabetic ketoacidosis.

$\mathbf{P}$ REVALENCE OF DIABETES continues to increase worldwide and now involves about half a billion people globally. ${ }^{1-3}$ The majority of this increase involves patients diagnosed with type 2 diabetes (T2D). ${ }^{3}$ Unfortunately, even today about $40 \%-50 \%$ of patients are undiagnosed. ${ }^{4}$ Recent data from the Centers for Disease Control and Prevention (CDC) show a slight increase in the prevalence of diabetes in the United States to be about $9 \%$ with about 84 million people with prediabetes. ${ }^{4}$ Type 1 diabetes (T1D) is also increasing worldwide at a rate of $\sim 3 \%-5 \%$ annually. ${ }^{5-8}$ This increase in patients with T1D involves not only the Western world but also emerging economies. ${ }^{3}$ Since there is a significant delay in diagnosing and initiating effective treatment for T2D, there is an ever-increasing number of patients requiring insulin. The total number of insulin-requiring patients today is expected to be around 150-200 million (by all means this is an underestimate). Thirty millions of these are patients with $\mathrm{T}^{6} \mathrm{D}^{6}$ of which 1.5-3 million are in the United States, a number that is likely to triple in the next three decades. ${ }^{8,9}$ About $10 \%-20 \%$ of patients with T2D are misdiagnosed (antibody positive), which makes about 40-80 million patients requiring insulin. ${ }^{10,11}$ Another $20 \%-30 \%$ of patients with T2D will require insulin therapy during the course of T2D due to significant beta cell loss over time and delays in diagnosing and initiating necessary treatments on time. ${ }^{10,12}$ Thus, cumulatively we have about $150-$ 200 million people requiring insulin therapy worldwide.

The majority of patients with diabetes (T1D and T2D) do not achieve target A1cs ( $<7 \%$ or $6.5 \%$ ) as recommended by the American Association of Clinical Endocrinologists (AACE), American Diabetes Association (ADA), European Association of Study for Diabetes (EASD), and other local/ national diabetes organizations. ${ }^{13-15}$ It is also unfortunate that about two-third of the patients with T1D are overweight or obese, ${ }^{16}$ and, of course, the majority of patients with T2D are either overweight or obese. ${ }^{1}$ Patients, especially those with T1D, also face morbidity and mortality risks from severe hypoglycemia and diabetic ketoacidosis. ${ }^{17,18}$

Recent guidelines by American College of Physicians published in Annals of Internal Medicine ${ }^{19}$ were ill-conceived and make no sense in recommending A1c goals to be $8 \%$ from $7 \%$ as recommended by global diabetes organizations. It adds confusion to a general practitioner for diabetes care.

Because of this tremendous increase in the number of patients, especially those requiring insulin therapy, the cost of healthcare related to diabetes and its complications is ever increasing. ${ }^{4,20}$ Global economic burden related to diabetes is expected to increase to 2.5 trillions of dollars annually by $2030 .^{21}$ It is estimated that global costs for all insulins alone have escalated to about 30 billion U.S. dollars, ${ }^{22}$ which is likely to continually increase. ${ }^{23,24}$ Part of this increase in the cost of all insulins is a disproportionate increase in costs (sometimes it is 5-10 times higher) in the United States. ${ }^{25-29}$

Total mortality rate in T1D and T2D is significantly higher than that in nondiabetic volunteers. ${ }^{4,29}$ Fortunately, the rate of almost all long-term complications of diabetes has been decreasing in the past two decades ${ }^{4,30}$; however, the total number of patients with those complications has been increasing because of the global increase in the prevalence of diabetes. ${ }^{30}$ The decrease in the rate of complications has been largely attributed to small but significant improvements in glycosylated hemoglobin, availability of several new therapies (new classes of drugs such as new longer acting and rapid-acting insulin analogues, Dipeptidyl peptidase IV (DPP IV) inhibitors, newer once a day or weekly Glucagon-like polypetide-1 (GLP-1) analogues, and Sodium-glucose transport protein 2 (SGLT-2) inhibitors) for managing diabetes effectively. ${ }^{31-34}$ In addition, the availability of several insulin analogues (insulin lispro, aspart, glulisine, FIasp, glargine, detemir, U300 glargine, and U100 and U200 degludec) ${ }^{35-43}$ allows effective intensive insulin therapy in insulin-requiring patients with no further increase in hypoglycemia despite improving glucose control, (which has usually been the hurdle to intensify insulin therapy). ${ }^{35,36,39}$ Last, but not least, the availability of new technologies such as continuous glucose monitors (CGMs), insulin pumps, and hybrid closed-loop systems has further advanced diabetes management without increase in hypoglycemia while achieving target A1cs. ${ }^{44-47}$

\footnotetext{
${ }^{1}$ Department of Medicine and Pediatrics, University of Colorado Denver, Aurora, Colorado.

${ }^{2}$ Barbara Davis Center for Diabetes, Aurora, Colorado.
} 
It is important to keep in mind that new technologies may not be the answer for the majority of the insulin-requiring patients because of increasing cost and difficulties in implementing these technologies in clinical practice. ${ }^{48}$ Currently, $<1 \%$ of insulin-requiring patients are using either insulin pumps alone and/or CGMs or hybrid closed-loop systems. ${ }^{11,49,50}$ The majority of patients using pumps are in the United States or in Western Europe. However, the need for insulin-requiring patients is far higher in the rest of the world, ${ }^{51}$ where cost is a major issue in implementing CGM or pump therapy. ${ }^{26}$ Thus, the majority of the insulin-requiring patients would benefit from an alternative platform that uses insulin-delivery pens that have memory functions (in development) in them, along with data being transmitted to a mobile device on an app. The patient's CGM/self-monitoring of blood glucose (SMBG) data would also transmit to the same app and thus advise them on day-to-day diabetes management.

In this supplement, Welsh focuses on the role of CGM in insulin-requiring patients, especially in T2D. ${ }^{52}$ They emphasize that the use of CGMs effectively improves glucose control without increasing hypoglycemia. In fact, it is important to note that the majority of the recent studies they included show that a large number of patients continue to use CGMs. In part, this may be due to improvement (accuracy) in technologies such that the majority of the currently available CGMs have an Mean Absolute Relative Difference of $<10 \% .^{52}$ In his review, Bob Ratner underscores the importance of hypoglycemia in diabetes care and how, in the near future, some of the newer insulin analogues might even get a favorable label change by the Food and Drug Administration (FDA). ${ }^{53}$

Helena Rodbard and Thomas Danne highlight the role of new GLP analogues, especially the those that can be used once a week (dulaglutide and semaglutide), and the new SGLT1 and SGLT2 inhibitors in diabetes care, respectively. ${ }^{54,55}$ Thomas Danne also highlights the possible adjunctive use of SGLT inhibitors in T1D (not yet approved by the FDA or European Medicines Agency (EMA)), in addition to their role in T2D. ${ }^{55} \mathrm{H}$. Kaan Akturk highlights the ways to improve postprandial glucose, especially using technosphere insulin (Afrezza, Mannkind, Inc., CA) due to the rapid onset of action (recent FDA label change). ${ }^{56}$

Weaver and Hirsch summarize the results of small studies related to different artificial pancreas systems showing no increase in hypoglycemia or ketoacidosis while emphasizing we are far from a system that replicates islet cell function in a fully automated multihormonal system. ${ }^{57}$

Lal et al. present emerging technologies including novel insulin, insulin delivery devices, glucose monitoring technology, and decision support systems that may be applicable for the majority of the insulin-requiring patients. ${ }^{58}$ Although SGLT1 and 2 inhibitors sound promising for patients with T1D, the proper mitigation plan for reducing the risk of diabetic ketoacidosis (DKA) is needed. ${ }^{55}$

Messer et al. discuss skin issues with the chronic use of insulin-delivery devices and CGMs. ${ }^{59}$ In addition to addressing these concerns, they offer prophylactic and alternative ways to reduce skin issues with these devices. ${ }^{59}$ David Rodbard emphasizes differences in glucose variability (GV) parameters in T1D and T2D, and the difficulties in implementing $\mathrm{GV}$ in clinical practice. ${ }^{60} \mathrm{He}$ also gives us a view into the future for new indices for possible GV. ${ }^{60}$ It is possible that in the near future, we will start quantifying glucose control not only by HbA1c but also by time-in-range, which may become a more important marker for day-to-day diabetes management. ${ }^{61}$ However, A1c measurements may be more important for population health and determining long-term complications of diabetes. Even though GV has never been proven to be an independent risk factor for long-term complications of diabetes, both patients and providers strongly believe that if GV can be effectively reduced, the quality of patients' life who require insulin therapy significantly improves. Tim Bailey, while stressing emerging technologies in diabetes care, also emphasize realistic expectations regarding artificial pancreas systems and the challenges in implementing the new technologies in daily clinical practice. ${ }^{62}$

I hope that you will enjoy and learn by reading this supplement. I sincerely want to thank all the authors who contributed in a timely manner to the supplement and the sponsors for providing an unrestricted educational grant to make this possible. We collectively need to have a clear message for the providers even though we might disagree. I strongly believe that the future is bright for patients with diabetes as they will continue to live longer with all the advances in the field. Unfortunately, the price of living longer that nobody talks about is the burden to the society that needs to be dealt appropriately.

\section{Author Disclosure Statement}

S.K.G. has received Advisory Board Consulting fees from Medtronic, Roche, Merck, Lexicon, Novo-Nordisk, Sanofi, Mannkind, Senseonics, Zealand, and Eli Lilly. S.K.G. has received research grants through the University of Colorado Denver from Eli Lilly, Novo-Nordisk, Merck, Lexicon, Medtronic, Dario, NCI, T1D Exchange, NIDDK, JDRF, Animas, Dexcom, and Sanofi. S.K.G. does not own stocks in any device or pharmaceutical company. Both A.H.R. and H.K.A. have no disclosures or conflicts of interest to report.

\section{References}

1. International Diabetes Federation: Diabetes Atlas, 7th ed. Brussels, Belgium, 2015.

2. Whiting DR, Guariguata L, Weil C, Shaw J: IDF diabetes atlas: global estimates of the prevalence of diabetes for 2011 and 2030. Diabetes Res Clin Pract 2011;94:311-321.

3. Cho NH, Shaw JE, Karuranga S, et al.: IDF Diabetes Atlas: global estimates of diabetes prevalence for 2017 and projections for 2045. Diabetes Res Clin Pract 2018;138:271-281.

4. Centers for Disease Control and Prevention: National Diabetes Statistics Report 2017. https://www.cdc.gov/diabetes/ pdfs/data/statistics/national-diabetes-statistics-report.pdf (accessed May 17, 2018).

5. Forlenza GP, Rewers M: The epidemic of type 1 diabetes: what is it telling us? Curr Opin Endocrinol Diabetes Obes 2011;18:248-251.

6. Garg SK, Henry RR, Banks P, et al.: Effects of sotagliflozin added to insulin in patients with type 1 diabetes. N Engl J Med 2017;377:2337-2348.

7. Mayer-Davis EJ, Dabelea D, Lawrence JM: Incidence trends of type 1 and type 2 diabetes among youths, 20022012. N Engl J Med 2017;377:301.

8. Dabelea D, Mayer-Davis EJ, Saydah S, et al.: Prevalence of type 1 and type 2 diabetes among children and adolescents from 2001 to 2009. JAMA 2014;311:1778-1786.

9. Imperatore G, Boyle JP, Thompson TJ, et al.: Projections of type 1 and type 2 diabetes burden in the U.S. population 
aged $<20$ years through 2050: dynamic modeling of incidence, mortality, and population growth. Diabetes Care 2012;35:2515-2520.

10. Turner R, Stratton I, Horton V, et al.: UKPDS 25: autoantibodies to islet-cell cytoplasm and glutamic acid decarboxylase for prediction of insulin requirement in type 2 diabetes. UK Prospective Diabetes Study Group. Lancet 1997;350:1288-1293.

11. World Health Organization: Diabetes. www.who.int/media centre/factsheets/fs312/en (accessed May 1, 2018).

12. Lipska KJ, Yao X, Herrin J, et al.: Trends in drug utilization, glycemic control, and rates of severe hypoglycemia, 2006-2013. Diabetes Care 2017;40:468-475.

13. McKnight JA, Wild SH, Lamb MJ, et al.: Glycaemic control of Type 1 diabetes in clinical practice early in the 21st century: an international comparison. Diabet Med 2015;32:1036-1050.

14. Miller KM, Foster NC, Beck RW, et al.: Current state of type 1 diabetes treatment in the U.S.: updated data from the T1D Exchange clinic registry. Diabetes Care 2015;38:971-978.

15. Schmittdiel JA, Uratsu CS, Karter AJ, et al.: Why don't diabetes patients achieve recommended risk factor targets? Poor adherence versus lack of treatment intensification. J Gen Intern Med 2008;23:588-594.

16. Weinstock RS, Schutz-Fuhrmann I, Connor CG, et al.: Type 1 diabetes in older adults: comparing treatments and chronic complications in the United States T1D Exchange and the German/Austrian DPV registries. Diabetes Res Clin Pract 2016;122:28-37.

17. Cryer PE: Mechanisms of hypoglycemia-associated autonomic failure in diabetes. N Engl J Med 2013;369:362-372.

18. Kitabchi AE, Umpierrez GE, Miles JM, Fisher JN: Hyperglycemic crises in adult patients with diabetes. Diabetes Care 2009;32:1335-1343.

19. Qaseem A, Wilt TJ, Kansagara D, et al.: Hemoglobin A1c targets for glycemic control with pharmacologic therapy for nonpregnant adults with type 2 diabetes mellitus: a guidance statement update from the American College of Physicians. Ann Intern Med 2018;168:569-576.

20. Zhuo X, Zhang P, Barker L, et al.: The lifetime cost of diabetes and its implications for diabetes prevention. Diabetes Care 2014;37:2557-2564.

21. Bommer C, Sagalova V, Heesemann E, et al.: Global economic burden of diabetes in adults: projections from 2015 to 2030. Diabetes Care 2018;41:963-970.

22. Close Concerns: https://www.closeconcerns.com/history.php (accessed March 13, 2018), San Francisco.

23. Rowley WR, Bezold C, Arikan Y, et al.: Diabetes 2030: insights from yesterday, today, and future trends. Popul Health Manag 2017;20:6-12.

24. Health Action International: The Addressing the Challenge and Constraints of Insulin Sources and Supply. http://haiweb .org/publication/acciss-study-report-access-insulin-currentchallenges-constraints (accessed March 13, 2018).

25. Tylee T, Hirsch IB: Costs Associated with using different insulin preparations. JAMA 2015;314:665-666.

26. Ogle GD, Kim H, Middlehurst AC, et al.: Financial costs for families of children with Type 1 diabetes in lower-income countries. Diabet Med 2016;33:820-826.

27. Good Rx: https://www.goodrx.com (accessed March 13, 2018).

28. Pharmaceutical Benefits Scheme: Australian Government Department of Health. http://www.pbs.gov.au/pbs/home (accessed March 13, 2018).
29. Med India: Network for Health. https://www.medindia.net (accessed March 13, 2018).

30. Centers for Disease Control and Prevention: Number of emergency department visits (in thousands) with hypoglycemia as first-listed diagnosis and diabetes as secondary diagnosis, adults aged 18 years or older, United States, 2006-2009. https://www.cdc.gov/diabetes/statistics/hypoglycemia/fig1.html

31. Marso SP, Daniels GH, Brown-Frandsen K, et al.: Liraglutide and cardiovascular outcomes in type 2 diabetes. N Engl J Med 2016;375:311-322.

32. Neal B, Perkovic V, Mahaffey KW, et al.: Canagliflozin and cardiovascular and renal events in type 2 diabetes. $\mathrm{N}$ Engl J Med 2017;377:644-657.

33. Garg SK: Role of emerging new technologies. Diabetes Technol Ther 2008;10:413-414.

34. Dandona P, Mathieu C, Phillip M, et al.: Efficacy and safety of dapagliflozin in patients with inadequately controlled type 1 diabetes (DEPICT-1): 24 week results from a multicentre, double-blind, phase 3, randomised controlled trial. Lancet Diabetes Endocrinol 2017;5:864-876.

35. Lane W, Bailey TS, Gerety G, et al.: Effect of Insulin degludec vs insulin glargine U100 on hypoglycemia in patients with type 1 diabetes: the SWITCH 1 randomized clinical trial. JAMA 2017;318:33-44.

36. Marso SP, McGuire DK, Zinman B, et al.: Efficacy and safety of degludec versus glargine in type 2 diabetes. $\mathrm{N}$ Engl J Med 2017;377:723-732.

37. Hermansen K, Davies M, Derezinski T, et al.: A 26-week, randomized, parallel, treat-to-target trial comparing insulin detemir with NPH insulin as add-on therapy to oral glucose-lowering drugs in insulin-naive people with type 2 diabetes. Diabetes Care 2006;29:1269-1274.

38. Rosenstock J, Dailey G, Massi-Benedetti M, et al.: Reduced hypoglycemia risk with insulin glargine: a meta-analysis comparing insulin glargine with human NPH insulin in type 2 diabetes. Diabetes Care 2005;28:950-955.

39. Riddle MC, Bolli GB, Ziemen M, et al.: New insulin glargine 300 units $/ \mathrm{mL}$ versus glargine 100 units $/ \mathrm{mL}$ in people with type 2 diabetes using basal and mealtime insulin: glucose control and hypoglycemia in a 6-month randomized controlled trial (EDITION 1). Diabetes Care 2014;37:2755-2762.

40. Renner R, Pfutzner A, Trautmann M, et al.: Use of insulin lispro in continuous subcutaneous insulin infusion treatment. Results of a multicenter trial. German Humalog-CSII Study Group. Diabetes Care 1999;22:784-788.

41. Heller SR, Colagiuri S, Vaaler S, et al.: Hypoglycaemia with insulin aspart: a double-blind, randomised, crossover trial in subjects with type 1 diabetes. Diabet Med 2004;21:769-775.

42. Garg SK, Rosenstock J, Ways K: Optimized Basal-bolus insulin regimens in type 1 diabetes: insulin glulisine versus regular human insulin in combination with Basal insulin glargine. Endocr Pract 2005;11:11-17.

43. Mathieu C, Bode BW, Franek E, et al.: Efficacy and safety of fast-acting insulin aspart in comparison with insulin aspart in type 1 diabetes (onset 1): a 52-week, randomized, treat-to-target, phase 3 trial. Diabetes Obes Metab 2018;20: $1148-1155$.

44. Garg SK, Weinzimer SA, Tamborlane WV, et al.: Glucose outcomes with the in-home use of a hybrid closed-loop insulin delivery system in adolescents and adults with type 1 diabetes. Diabetes Technol Ther 2017;19:155-163.

45. Bergenstal RM, Garg S, Weinzimer SA, et al.: Safety of a hybrid closed-loop insulin delivery system in patients with type 1 diabetes. JAMA 2016;316:1407-1408. 
46. Beck RW, Riddlesworth T, Ruedy K, et al.: Effect of continuous glucose monitoring on glycemic control in adults with type 1 diabetes using insulin injections: the DIAMOND randomized clinical trial. JAMA 2017;317: 371-378.

47. Lind M, Polonsky W, Hirsch IB, et al.: Continuous glucose monitoring vs conventional therapy for glycemic control in adults with type 1 diabetes treated with multiple daily insulin injections: the GOLD randomized clinical trial. JAMA 2017;317:379-387.

48. Rodbard D: Continuous glucose monitoring: a review of successes, challenges, and opportunities. Diabetes Technol Ther 2016;18 Suppl 2:S3-S13.

49. Insulin Pumps Need Greater Safety Review: American Diabetes Association Issues Joint Statement with European Association for the Study of Diabetes. www.diabetes.org/ newsroom/press-releases/2015/insulin-pumps.html (accessed May 1, 2018).

50. Grunberger G, Abelseth JM, Bailey TS, et al.: Consensus statement by the American Association of Clinical Endocrinologists/American College of Endocrinology insulin pump management task force. Endocr Pract 2014;20: $463-489$.

51. Liu C, Zhang X, Liu C, et al.: Insulin prices, availability and affordability: a cross-sectional survey of pharmacies in Hubei Province, China. BMC Health Serv Res 2017; 17:597.

52. Welsh JB: Role of continuous glucose monitoring in insulinrequiring patients with diabetes. Diabetes Technol Ther 2018;20 Suppl 2:S2-42-S2-49.

53. Ratner RE: Hypoglycemia: New definitions and regulatory implications. Diabetes Technol Ther 2018;20:Suppl 2:S250-S2-53.

54. Rodbard H: The clinical impact of GLP-1 receptor agonists in type 2 diabetes: Focus on the long-acting analogs. Diabetes Technol Ther 2018;20 Suppl 2:S2-33-S2-41.
55. Danne T, Biester T, Kordonouri O: Combined SGLT1 and SGLT2 inhibitors and their role in diabetes care. Diabetes Technol Ther 2018;20 Suppl 2:S2-69-S2-77.

56. Akturk HK, Rewers A, Joseph H, Schneider N, Garg SK: Possible ways to improve postprandial glucose control in type 1 diabetes. Diabetes Technol Ther 2018;20 Suppl 2: S2-24-S2-32.

57. Weaver KW, Hirsch IB: The hybrid closed-loop system: evolution and practical applications. Diabetes Technol Ther 2018;20 Suppl 2:S2-16-S2-23.

58. Lal RA, Buckingham B, Maahs DM: Advances in care for insulin-requiring patients without closed loop. Diabetes Technol Ther 2018;20 Suppl 2:S2-85-S2-91.

59. Messer L, Berget C, Beatson C, et al.: Preserving skin integrity with chronic device use in diabetes. Diabetes Technol Ther 2018;20 Suppl 2:S2-54-S2-64.

60. Rodbard D: Glucose Variability: A review of clinical applications and research developments. Diabetes Technol Ther 2018;20 Suppl 2:S2-5-S2-15.

61. Riddlesworth TD, Beck RW, Gal R, et al.: Optimal sampling duration for continuous glucose monitoring to determine long-term glycemic control. Diabetes Technol Ther 2018;20: 314-316.

62. Bailey TS, Walsh J, Stone JY: Emerging technologies for diabetes care. Diabetes Technol Ther 2018;20 Suppl 2:S278-S2-84.

Address correspondence to: Satish K. Garg, MD

Professor of Medicine and Pediatrics Barbara Davis Center for Diabetes 1775 Aurora Court, A140 Aurora, CO 80045

E-mail: satish.garg@ucdenver.edu 